\section{LA GIMNÁSTICA COMO DISPOSITIVO ANTIONANISTA EN LA CONFORMACIÓN DE LA EDUCACIÓN FÍSICA ESCOLAR EN EL SIGLO XIX EN ESPAÑA: EL NACIMIENTO DE UNA DISCIPLINA ESCOLAR}

\author{
GYMNASTICS AS AN ANTI-ONANISTIC TOOL IN SHAPING SCHOOL PHYSICAL \\ EDUCATION IN 19TH-CENTURY SPAIN: THE BIRTH OF A SCHOOL DISCIPLINE
}

A GINÁSTICA COMO DISPOSITIVO ANTIONANISTA NA CONFORMAÇÃO DA EDUCAÇÃO FÍSICA ESCOLAR DO SÉCULO XIX NA ESPANHA: O NASCIMENTO DE UMA DISCIPLINA ESCOLAR

Xavier Torrebadella-Flix*, Miguel Vicente-Pedraz**
Palabras clave

Salud escolar.

Masturbación.

Gimnasia.

Historia del siglo

XIX.

Keywords

School health

Masturbation.

Gymnastics. 19th-

century history.
Palavras-chave

Saúde escolar. Masturbação.

Ginástica.

História do século XIX.
Resumen: Este artículo complementa uno anterior publicado en esta revista (v. 21, n. 4, oct./dic. 2015). A partir de la revisión y análisis de contenido de la materia médica, pedagógica y gimnástica publicada en España en el siglo XIX, verificamos que la prescripción facultativa de la gimnástica constituyó el núcleo de la política preventiva y terapéutica contra la masturbación infantil. Dicha política -disciplinaria y normalizadora según el modelo centroeuropeo- fue asumida paulatinamente por los establecimientos escolares que concedieron un tiempo y un espacio regulares a la práctica gimnástica. Ésta, una vez desprendida de los elementos ideológicos y morales más controvertidos del adoctrinamiento del cuerpo, acabaría conformando la educación física escolar que conocemos.

Abstract: This paper follows up on an earlier work published in this journal (v. 21, no. 4, Oct./Dec. 2015). By reviewing and analyzing the content of medical, pedagogic and gymnastic material published in Spain in the 19th century, we established that medical prescription of gymnastics was the core of preventative and therapeutic policies against child masturbation. That disciplinary and normalizing policy based on the Central European model was gradually adopted by school establishments that dedicated regular time and space to the practice of gymnastics. Once it separated itself from the most controversial ideological and moral elements of body indoctrination, gymnastics became the Physical Education found in schools today.

Resumo: Este artigo complementa um anterior publicado nesta mesma revista (v. 21, n. 4, out./dez. 2015). A partir da revisão e análise de material médico, educacional e ginástico publicado na Espanha no século XIX, verificou-se que a prescrição de ginástica foi o centro da política preventiva e terapêutica contra a masturbação das crianças. Essa política - disciplinar e de normalização de acordo com o modelo centro-europeu - foi gradualmente assumida pelas escolas, que concederam um tempo e um espaço regular na prática da ginástica. Esta, depois de afastada dos elementos mais controversos da doutrinação ideológica e moral do corpo, acabaria constituindo a Educação Física Escolar que conhecemos.
* Universidad Autónoma de Barcelona. Barcelona, España.

E-mail: gtorreba@gmail.com

** Universidad de León. León, España. E-mail: mvicp@unileon.es

Recebido em: 05-03-2015 Aprovado em: 02-07-2015 (c) (i) () Licence 


\section{INTRODUCCIÓN}

El desarrollo de los discursos y las prácticas fundacionales de la gimnasia en tanto que dispositivo antionanista en España no sigue un movimiento lineal y continuo. Se configura, más bien, por irradiación, avance y retroceso, acumulación y sustracción a partir de la recepción de algunas de las obras más emblemáticas del momento en el contexto del centro y sur de Europa; particularmente, las del ámbito francófono del cual fue precursora la obra del suizo Tissot (1760) L'Onanisme. Dicha configuración se inscribe, no obstante, en la dinámica de transformaciones propias de los estados liberales del siglo XIX en el sentido de que surgen por un interés disciplinario anatomopolítico -en torno al sujeto- para configurarse paulatinamente como estrategias de control biopolítico - de carácter poblacional-.

Respecto de la configuración de la gimnasia higiénica y educativa, los distintos discursos y prácticas que conformaron la cruzada antionanista acabaron definiendo cierto modo de adscripción política del cuerpo que daba forma a la educación física escolar en tanto que dispositivo (microfísico) de encauzamiento de la conducta; es decir, en tanto que mecanismo administrativo y político, moderno y urbano, aplicado al arte de gobernar el cuerpo.

En un artículo anterior (VICENTE-PEDRAZ; TORREBADELLA-FLIX, 2015), del que este es complementario y continuación, señalábamos que en el proceso de configuración de la gimnástica antionanista en España había que distinguir dos periodos. El primero, analizado en dicho artículo, se correspondía con la etapa de conformación del higienismo liberal en España; comprendía aproximadamente la primera mitad del siglo XIX y quedaba definido por la recepción y traducción al castellano de obras europeas. Por su parte, el segundo periodo, del que nos ocupamos específicamente en esta ocasión, abarcaría desde mediados de los años cuarenta hasta finales de siglo, en pleno apogeo del regeneracionismo.

\section{DEL HIGIENISMO LIBERAL A LA MEDICINA SOCIAL}

Aunque la delimitación conceptual entre higienismo liberal y medicina social continúa siendo materia de debate (QUINTANAS, 2011), la naturaleza y contexto de cada una de estas dos corrientes nos permitirá determinar los elementos característicos de la cruzada antionanista y su papel en la conformación de la educación física escolar en España.

A este respecto, si el higienismo liberal se puede asociar con la corriente de pensamiento médico ilustrado, orientado a la búsqueda del orden moral y físico y con ellos a la estabilidad social, por medicina social entendemos a los procesos de intervención directa sobre la salud y las condiciones de vida de la ciudadanía aplicados a escala colectiva y que eclosionan a partir de la segunda mitad del siglo XIX. Se corresponde con el tipo de acciones de control sanitario aplicadas de forma centralizada y estatalizada-como le era propio a los denominados estados interventores de finales de siglo - a través de disposiciones, leyes y organismos ministeriales, instituciones creadas ad hoc para velar por el bien común, la prosperidad nacional, la regeneración, etc. mediante políticas de control que, no obstante, siguieron amparándose en los principios de orden moral y físico de acuerdo, ahora, con la noción foucaultiana de biopolítica.

Si hay una figura que pueda representar la transición entre el higienismo liberal y la medicina social en la España del XIX, esa es sin duda la del médico Felipe Monlau (18081871) cuyas obras, si bien por tiempo e ideología aún pertenecían al liberalismo, anunciaban la 
transición a los modelos sanitarios de corte intervencionista. Por otra parte, Monlau ya no es un mero transmisor de las ideas sanitarias europeas; Monlau inaugura un periodo de producción higiénico-médica autóctona en el que se pone de relieve la necesidad de imponer un control estatal de buen gobierno corporal.

A este respecto influido directamente por Miguel Lévy, profesor de higiene y de medicina en el Hospital Militar de París, Monlau se interesaba por la cuestión antionanista y advertía de los riesgos que el placer solitario suponía:

Cuando un niño adelantado o un joven pierden el color y flaqueen aunque coman mucho; cuando se les ve aficionados a la soledad, apartándose de los juegos de sus compañeros, etc.; es muy prudente sospechar que ha contraído el ruidoso hábito de abusar de sí mismos (MONLAU, 1846, p. 469).

Monlau recomendaba entonces avisar al médico y entre los muchos medios para evitar las excitaciones aconsejaba los baños de agua fría, dejar de comer carnes y bebidas fermentadas, dejar de leer novelas, de asistir a los bailes y teatros, dormir boca arriba además de «los ejercicios muy activos y prolongados hasta el cansancio o el rendimiento» (MONLAU, 1846, p. 470). Asimismo, y como medio preventivo, parafraseando a Lallemand y a Lévy prescribía "la gimnasia obligatoria, variada y ajustada a cada edad" (MONLAU, 1846, p. 774775) y una estrecha vigilancia en los establecimientos públicos:

[...] este vicio es casi endémico en los colegios, en toda reunión de jóvenes. Con este motivo será fuerza recordar que nuestro sistema de educación y de instrucción demanda profundas reformas. Las contenciones del espíritu son demasiado prolongadas y los ejercicios corporales demasiado insuficientes (MONLAU, 1847, p. 742-743).

En esa misma línea de pensamiento, pero imprimiéndole mayor severidad en el tono -que bien podría calificarse de apocalíptico- se expresa Torres. En Educación física o el libro de la salud, atribuía a la masturbación el deterioro de "las facultades de los órganos principales y de toda la economía" además de ser la causa de enfermedades graves e indisposiciones permanentes de la salud "precipitándose irreversiblemente al término de la existencia" (TORRES, 1853, p. 27). Ante tan calamitosas perspectivas recomendaba, cómo no:

[...] hacer diariamente ejercicios activos, variados y frecuentes que pongan en particular en acción los músculos de los brazos y del pecho, como la lucha, la esgrima, el juego de pelota, la natación en verano. Los ejercicios gimnásticos, etc. para que se tenga necesidad de descanso (TORRES, 1853, p. 27).

Pero como hemos apuntado, las traducciones no cesan en este periodo. Así, en sentido parecido, Grisolle cuyo Tratado elemental y práctico de patología interna advertía que "Todos los medios coercitivos que al efecto se han imaginado son insuficientes o peligrosos y tampoco basta la vigilancia más asidua y sagaz". Y como profilaxis de lo que denominaba "espermatorrea", apuntaba también a los ejercicios corporales: "En estos casos debe recurrirse especialmente a los ejercicios corporales, como los paseos, la natación, la esgrima, para disminuir la actividad de los órganos genitales" (GRISOLLE, 1857, p. 373).

Resulta sobremanera característica de entre las traducciones de mediados de siglo la obra La conservación personal de La Mert (1849), por cuanto constituye tal vez la más clara avanzadilla en materia higiénico-sanitaria de lo que décadas después serán las formulaciones regeneracionistas. La Mert hace referencia expresa a la decadencia 
prematura de la energía física y mental y demás atributos de la virilidad, leit motif de dicha corriente, dirigido a quienes padecían enfermedades de los órganos de la generación $y$, asimismo, para evitar las llamadas poluciones involuntarias o las perdidas seminales (VÁZQUEZ GARCÍA; MORENO MENGÍBAR, 1997). La obra de La Mert tiene además la particularidad de ser publicada en prensa en lo que se puede interpretar como un decidido propósito de divulgación de los preceptos higiénico-morales de educación física entre las familias de la pequeña burguesía:

Con la lectura de este libro -señala- la madre cariñosa aprenderá los cuidados que deberá prodigar a sus hijas, para dirigir su educación física a fin de evitar, no solo los funestos efectos de habitudes secretas, sino de las obstrucciones y flujos que trastornan las bellas formas y la hermosura de la mujer, presentando un aspecto de extrema debilidad, consumición, palidez, aun la posibilidad de ser madres, causas de tantas disensiones en las familias (Libros, Diario oficial de avisos de Madrid, 7 de junio de 1849, p. 3).

Es llamativa, en este contexto de eclosión disciplinaria, las consideraciones que realiza Teste quien, a pesar de no recomendar el ejercicio físico contra el onanismo, ideó un completo sistema de vigilancia con el que se "rodeará a los niños de noche y de día, y envolverá su red hasta los actos más íntimos" (TESTE, 1850, p. 126). Igualmente llamativos son los planteamientos de Descuret en su Medicina de las pasiones (1857); en lo que constituye un ejemplo claro del desdibujamiento de las fronteras ente lo privado y el control público, instruye acerca de cómo estrechar el cerco al niño mediante "una vigilancia incesante" de los padres quienes, a la más mínima sospecha, habían de avisar al médico y a ser posible "cogerlo in fraganti' (DESCURET, 1857, p. 276). La recomendación contra tales pasiones, cómo no, eran viajes a pie, natación y otros ejercicios gimnásticos antes de acostarse, para alcanzar la fatiga. $Y$ es que, como señala Laqueur, "el vicio privado se había vuelto una cuestión de fundamental de la política pública" (LAQUEUR, 2007, p. 62-63).

Si bien no resulta sorprendente que tratados higiénicos españoles se ocupen de la depravación onanista, reproduciendo prácticamente todos cuantas enfermedadesy corrupciones y físicas había achacado la literatura higiénico-médica francesa a la perversión masturbación (debilitamiento mental, cretinismo nervioso, desviación de la columna vertebral, palidecimiento cutáneo, afeminamiento de los varones, sífilis, etc.), sí resulta un tanto curioso que tratados enciclopédicos se emplearan a fondo en el asunto. Este es el caso de la Enciclopedia moderna de Mellado que, en todo caso, pone de relieve la preocupación social por el asunto más allá de los círculos estrictamente médicos. Mellado prevenía contra el "contagio" de este vicio en los establecimientos públicos donde se reunía gran número de jóvenes de uno y otro sexo y recomendaba también la gimnasia como mejor antídoto contra la ociosidad y el tormento de las pasiones sexuales:

[...] jamás se insistirá bastante acerca de las ventajas de la gimnasia porque es aplicable a todas las edades y a todos los sexos, y por lo mismo debería formar parte esencial de la educación pública. Donde quiera que haya establecimientos para ejercicios gimnásticos, se obtienen resultados que parecen verdaderos prodigios (MELLADO, 1854, p. 189-190).

A este respecto, tomando el testigo de lo que ya estaba sucediendo en Francia, Mellado planteó abiertamente la inclusión de la gimnasia en las escuelas como estrategia, no tanto moralizante como disuasoria, contra el onanismo: 
En algún que otro establecimiento se han introducido los ejercicios gimnásticos para las horas de recreo pero estas son pocas y el estudio es excesivo para los tiernos niños cuya educación tiene que ser más física que moral [...] y su cuerpo fatigado con ejercicios violentos, no le dejan espacio para entregarse a aquella especie de inquietud vaga que atormenta a los jóvenes ociosos (MELLADO, 1854, p. 186).

La cuestión llega a concitar, incluso, la defensa de tesis doctorales en la Facultad de Medicina de la Universidad Central con el tema "Influencia de la gimnástica en el desarrollo y vigor de la organización del hombre" (TORREBADELLA FLIX, 2012). En dicha defensa, Miguel Vinaja calificaba la gimnástica como uno de los auxilios más eficaces para evitar las "ocultas excéntricas pasiones que encaminan a la depravación y al vicio aniquilando por instantes su existencia" (VINAJA CABALLERO, 1860, p. 19-20); José Lorenzo Grasa decía de la natación que era "muy útil a los jóvenes ardientes e inclinados a placeres solitarios" (GRASA PÉREZ, 1861, p. 18); Paz Álvarez subrayaba que siempre había que tener presente que en las inmediaciones de la pubertad es cuando la gimnasia y la fatiga muscular "proporciona la calma necesaria al sistema nervioso, y preserva a los jóvenes de las más funestas costumbres" (ÁLVAREZ GONZÁLEZ, 1863, p. 22-23); Manuel Ortega indicaba que "la gimnasia, continuando la obra empezada en la infancia y con el auxilio de los buenos preceptos morales ya inculcados, se opondrá al furor de esas pasiones mitigando la ardiente sed de satisfacerlas" (ORTEGA FERNÁNDEZ, 1866, p. 12-13).

El doctor Busqué y Torró, considerado el autor del primer tratado de rehabilitación mediante la gimnástica en España, exponía con insospechada locuacidad algunas de las más extrañas explicaciones que se podían llegar a plantear sobre el estado de la cuestión:

La influencia depresiva de la inteligencia, el ataque directo a la inervación ganglionar, el empobrecimiento de la sangre, de que el onanismo es causa, se constituyen a su vez motivo de esa susceptibilidad nerviosa, de esa constitución de delicada que predispone a toda clase de enfermedades y a las muertes prematuras por la tuberculosis. Por eso, nunca se encarecerá bastante la utilidad, la conveniencia, la imprescindible obligación de los padres y tutores de mantener vigilancia esmerada cuando se sospeche un vicio de tanta trascendencia: y en caso, reprenderle severamente y sujetar al individuo a los trabajos corporales, a la equitación, a los ejercicios gimnásticos para gastar una actividad superflua, y llevar la vida a los músculos y a la nutrición; único medio de acallar manifestaciones precoces y de rehabilitar las pérdidas que han determinado (BUSQUÉ, 1865, p. 127-128).

Por la misma época, Juan Goux se dirigía a los padres de familia indicándoles que su método gimnástico había logrado resolver todos los vicios de conformación congénitos y adquiridos. Planteaba enderezar el "árbol de la conformación viciosa", antes que "verlos destinados a perecer por una muerte precoz" e indicaba que el vicio de la masturbación era causa de "casi todas las enfermedades encefálicas" (GOUX, 1866, p. 8).

Joaquín Lladó en un popular tratado titulado Nociones de gimnasia higiénica, aplicables a las escuelas de instrucción primaria de uno y otro sexo como elementos de educación física, ya no consideraba incidir en la:

[...] influencia inmensa que el ejercicio tiene en la juventud para apartarla de vicios repugnantes; todos los higienistas, todos los médicos lo indican para que unido a los consejos religiosos produzca saludables resultados (LLADÓ, 1868, p. 111). 
También Seraine y Fonssagrives, traducidos y muy divulgados en España, anunciarían poco después algunos de los principios regeneracionistas, consecuentes con la mutación del higienismo liberal y sus mecanismos de control anatomopolíticos hacia los modelos de la medicina social de corte biopolítico. Seraine apeló en Higiene física y moral de los niños a la masturbación como causa de la degeneración de la especie ofreciendo consejos a padres y maestros; consejos para evitarla "[...] pues, aplicar todos sus sentidos, a cuidar de que el instinto generador no se desenvuelva antes del tiempo fijado por la naturaleza" (SERAINE, 1876, p. 145).

Por su parte Fonssagrives planteaba que el onanismo era una plaga degenerativa a la altura de la sífilis o el alcoholismo debiendo cuya contaminación tenía lugar en las escuelas (FONSSAGRIVES, 1887).

Aunque las referencias a la masturbación femenina siguen siendo en este periodo tan escasas como en el anterior, las pocas referencias encontradas al respecto tendían a legitimar el heredado cliché del cuerpo femenino como cuerpo carente, como cuerpo esencialmente enfermizo. Así por ejemplo, Debreyne aportaba una obra dirigida especialmente a los religiosos en las que también recordaba a Deslandes y repetía que "una culpable negligencia en las pensiones de señoritas, hace que se introduzca con frecuencia los desórdenes de la masturbación" (DEBREYNE, 1855, p. 81). Sostenía que, por causa de la mala educación y moral y la corrupción de las costumbres, el onanismo se había frecuentado de forma deplorable hasta el punto de que:

[...] gran número de niñas y casi todas las adolescentes se masturban; del mismo modo que no hay joven alguno al que no deba considerarse como entregado 0 muy expuesto a entregarse próximamente al onanismo (DEBREYNE, 1855, p. 81).

A este respecto, pese a los procesos de feminización de la sociedad del siglo XIX (FERNÁNDEZ, 2004), la gimnástica femenina también apareció en los colegios para sanar ese cuerpo enfermizo; para corregir las desviaciones sexuales de la mujer y cimentar un cuerpo sumiso al control de la masculinidad (TORREBADELLA FLIX, 2013c).

\section{EL ANTIONANISMO EN EL ÁMBITO PEDAGÓGICO: EL NACIMIENTO DE UNA DISCIPLINA ESCOLAR}

El análisis de la producción higiénico moral decimonónica no deja lugar a dudas sobre la influencia que la cruzada antionanista tuvo en el desarrollo de la cultura gimnástica en el centro y sur de Europa. El creciente prestigio social de la clase médica fue un condicionante decisivo para que dicha cultura arraigara, al menos entre las clases acomodadas, dadas las débiles estructuras de los Estados liberales en lo referente al mantenimiento de las condiciones de salubridad individual y colectiva y también en lo referente al adoctrinamiento higiénico-moral. Para las clases populares, sin acceso a la medicina, este papel lo desempeñaría un incipiente cuerpo de maestros que - pese a las disputas sociales e incluso ideológicas con la clase médica - desde muy pronto se haría partícipe de los modelos higiénico-morales que aquellos defendían.

En este sentido, se puede decir que la cruzada higiénica formó dos frentes que, de manera no planificada, coadyuvaron, cada uno desde su posición y en su ámbito de influencia, en la dirección de un creciente control del cuerpo en todos los estratos sociales. Aunque, dentro del discurso del autocontrol higiénico-moral, es difícil distinguir cuándo los preceptos actúan como dispositivo de salubridad médica y cuándo como dispositivo pedagógico 
propiamente dicho, la identificación de episodios, iniciativas, actuaciones, alegatos, etc., que con sorprendente recurrencia se fueron sucediendo en el ámbito de la escuela, nos pone sobre la pista de cómo las preocupaciones sociales en torno al control del cuerpo dieron lugar a la aparición de la educación física.

Las primeras manifestaciones oficiales al respecto se remontan a 1830 cuando el Plan de educación física y moral presentado en Cádiz ante las cortes apelaba, aun sin mencionar expresamente el onanismo, al carácter disuasorio del cansancio muscular producido por la gimnasia:

Su utilidad es todavía más conocida si se la considera como uno de los medios más poderosos para corregir ciertos hábitos viciosos, que advierten generalmente en los colegios, casas de educación y aún en las casas particulares. La gimnástica llena todos los instantes que no se desestiman a ejercitar el entendimiento: forman parte del recreo, y como exige del empleo de todas las fuerzas, dispone los muchachos a un sueño profundo, proporcionándoles un descanso apacible, que aleja todo pensamiento dañoso (PLAN DE EDUCACIÓN FÍSICA Y MORAL, 1830, p. 5).

Pocos años después, el reglamento del recién constituido Colegio Español Hamiltoniano, dirigido por el erudito clérigo sevillano Alberto Lista, incorporaba la práctica de ejercicios gimnásticos según unos procedimientos cuya orientación pone de relieve la celosa vigilancia para prevenir cualquier desliz así como las medidas correctoras:

[cuando los maestros] en tiempo de los calores aconsejen los baños, los alumnos irán a bañarse conducidos por el mismo señor censor, vice-censor, pasantes 0 celadores, y acompañados por dos maestros de natación; al efecto llevarán calzoncillos y capas de lienzo [...]. Atendida la necesidad de una vigilancia incesante y bien atendida sobre las buenas costumbres de los discípulos, estos serán visitados el primer jueves de cada mes por los médicos del colegio (COLEGIO ESPAÑOL HAMILTONIANO, 1838, p. 8).

Como si de una extensión del ojo escrutador paterno se tratara, Alberto Lista concebía la institución como una especie panóptico hasta el punto de que en los discursos de inauguración del Colegio prometía a los padres de los alumnos tomar todas las medidas para vigilar en todo momento el comportamiento higiénico y moral de los educandos en la creencia, de acuerdo con lo que Foucault denominó sociedad disciplinaria (FOUCAULT, 2012), que la institución educativa siempre debía permanecer observadora.

La combinatoria de vigilancia y gimnasia, según la concepción disciplinaria en marcha, se pone especialmente de relieve en la obra del que es considerado el principal promotor de la gimnástica en los colegios de Madrid, Francisco Aguilera, Conde de Villalobos. Aguilera sentenciaba que para reparar los daños del onanismo no eran suficientes, ni la estrecha vigilancia, ni el empleo de aparatos mecánicos; solo en:

[...] la gimnasia sin duda se encuentra el más poderoso recurso para remediarlos, por ser el medio más eficaz de repartir entre todos los órganos de la economía esa aglomeración de vitalidad, que se hace la causa de tan dañosos efectos (AGUILERA, 1845, p. 17-18).

Un poco más tarde, casi mediado el siglo XIX, el Reglamento del Colegio Naval Militar de San Carlos -cuyo ingreso estaba reservado a niños de entre 11 y 14 años que acreditasen una certificación facultativa de robustez y aptitud física- incluía, entre las materias accesorias para la formación de los oficiales de marina, natación, esgrima, baile y gimnasia. Dicho 
reglamento establecía, además, la organización de los espacios en las horas de recreo con el objeto de facilitar juegos y ejercicios precisando, en un controvertido artículo 104, que el personal encargado de la vigilancia:

[...] no permitirá que los aspirantes se separen por motivo alguno del paraje destinado a este objeto, cuidando de que sus diversiones no puedan perjudicar a su edad, ni sean impropias del decoro que siempre deben conservar (COLEGIO NAVAL MILITAR, 1848, p. 153).

Que los médicos aconsejaran la gimnástica como medio preventivo y reparador ante la ruina higiénica y moral de la masturbación, en un momento en que la medicina hacía acopio de funciones directivas en la sociedad, permite explicar, al menos en parte, la incorporación de ejercicios corporales y el establecimiento de los primeros gimnasios en colegios privados laicos pero también en las incipientes instituciones para el cuidado infantil ajenas a los establecimientos escolares en la primera mitad de siglo (TORREBADELLA FLIX, 2013a; 2013b). Este es el caso, por ejemplo, del conocido gimnasio de la Sociedad Gimnástica Infantil sito en la calle del Colmillo, 6 de Madrid (SECCIÓN..., 1850, p. 4).

De entre los gimnasios que a tal efecto se crearon dentro de las escuelas laicas destacan, ambos de 1847, el del Colegio de № Señora de Loreto y el del Colegio Politécnico de Madrid. En el primero, Teresa Castellanos de Mesa -fundadora de las clases de gimnástica en dicho centro- seguía el método de Clias bajo supervisión facultativa para evitar deformaciones de la columna vertebral y de las piernas y, asimismo, anunciando lo ventajoso que eran los ejercicios "para las niñas cuando se hallan en el periodo de la pubertad" y para "librarlas de las enfermedades interiores" (GACETILLA..., 1850, p. 4).

El segundo, fundado por iniciativa de la aristocracia madrileña (SIMÓN PALMER, 1972, p. 253-254), se revela como todo un programa higiénico-moral cuyas intenciones resultan sorprendentemente expeditivas. Bajo la dirección del presbítero Julián González de Soto, no se escatimaron medios en el colegio para lograr la perfecta educación intelectual, moral y física que, de acuerdo con los ideales aristocráticos de sus fundadores, incluía clases de adorno, de gimnasia, de baile, de esgrima, de equitación o natación (MADOZ, 1850, p. 805-806). No obstante, al lado del sello distintivo que podía aportar el dominio del cuerpo a través de su ejercitación, el ideario educativo de la institución no se sustrajo al poder de convicción que la gimnástica había acumulado en términos morales 0 , dicho de otro modo, como dispositivo contra la masturbación. Julián González incorporó, a este respecto, un programa de educación en el que los estudios se alternaban con gimnástica y múltiples aunque cortos recreos de 15 minutos; porque si son largos, apuntaba, "los hay que se retiran a parajes menos públicos, donde los adelantados abren escuela tenebrosa" (GONZÁLEZ, 1850, p. 15).

Evidentemente, en esta batalla por la honestidad de los colegiales, la Iglesia no podía quedar al margen. Como señalan Vázquez y Seoane la iglesia católica, liderada por el arzobispo y confesor de Isabel II Antonio María Claret, tomó partido en la batalla contra esta peste desoladora de la juventud. Así, en la introducción al "Bálsamo eficaz para curar un sinnúmero de enfermedades del alma y cuerpo" -opúsculo al servicio de maestros, confesores y padres (VÁZQUEZ GARCÍA; SEOANE CEGARRA, 2004, p. 835-868), Claret instruía sobre la aplicación de remedios seguros contra la funesta enfermedad: 
de la masturbación Yo me atrevo á asegurar que el que de ellos lea con atención lo que este librito contiene y practique los remedios espirituales de higiene que prescribe corregirá su vicio y reformará sus costumbres con grandes ventajas para el alma y para el cuerpo (CLARET, 1852, p. 6-7).

Pero el cuerpo no quedaría señalado solo como un mero complemento de la higiene espiritual que prescribía Claret. En 1861, el arzobispo instaló en el Colegio de segunda enseñanza de El Escorial un completo gimnasio coincidiendo con la publicación de El Colegial o seminarista (1865) (COLEGIO, 1865, p. 1); un libro de texto expeditivo para la formación doctrinal en las escuelas seminaristas del Reino donde dedicaba un capítulo entero a la educación física y los juegos gimnásticos.

De todos modos, la prescripción y el empleo de la gimnasia en la lucha contra la masturbación no se detendría ahí; a la vez que los adalides de la virtud conquistaban el terreno de la medicina y el francamente asequible espacio de los establecimientos eclesiásticos para tales preceptos, la ofensiva antionanista hacía sus escarceos en el ámbito de la educación pública. A este respecto, el adoctrinamiento higienista fue abrazado por algunos de los más ilustres e influyentes tratadistas de la pedagogía española de mediados del XIX como Laureano Figuerola o Joaquín Avendaño y Mariano Carderera quienes aconsejaban la inclusión de la educación física en las escuelas a base de juegos corporales y gimnasia. En uno y otros, el discurso disciplinario a propósito de la vigilancia y la coerción en el proceso de conformación de la subjetividad, en el sentido foucaltiano, alcanza una notable dimensión.

Por ejemplo, Figuerola advertía del papel vigilante que había de adoptar el maestro ante lo que consideraba rasgos fisionómicos de la obscenidad:

[aquello] que más debe llamar la atención del maestro es esa peste de malos hábitos, que propagan la ociosidad y las diversiones [...] Desconfíe el maestro de aquellos niños de fisonomía triste, ojos hundidos, lánguidos y rodeados de un color lívido; de aquellos que buscan la soledad y huyen de los juegos en que se requiere actividad, que gustan de estar sentados, y cuya inteligencia, en lugar de desarrollarse parase entorpecerse cada día más (FIGUEROLA, 1842, p. 173).

y no dudaba en aconsejar la amenaza y hasta el escarnio público para con los infractores, puesto que la

[... vergüenza de verse descubiertos, la relación de los peligros que les amenazan y los males que les aguardan, producen un efecto saludable en aquellos que no están enteramente pervertidos [...] pues se trata de preservar a los demás de un ejemplo funesto (FIGUEROLA, 1842, p. 173).

En parecido sentido se expresaban Avendaño y Caderera, deudores de los modelos doctrinales punitivos establecidos en Alemania por Niemeyer, Schwarz o en Francia por Rendu. Precisamente, siguiendo a Rendu (1845), Avendaño y Carderera aleccionaban a los maestros para que adoptaran precauciones generales contra la corrupción y el vicio; les aconsejaban expulsar de la escuela a un niño cuando se descubriera como incitador. Los rasgos, tan a menudo invocados para identificar los culpables del vicio, los definían del siguiente modo:

La palidez del semblante y particularmente de los labios, en cambio pronto y frecuente del color, los ojos hundidos, cóncavos, sombríos, agitados; el relajamiento de los músculos del rostro, la turbación cuando se les mira, los granos en la cara, el mal olor del aliento, una extenuación, en fin, a cada esfuerzo, son los síntomas ordinarios de haber contraído este vicio; aunque estos mismos signos puedan resultar también alguna vez de un estado prolongado de flaqueza y enfermedad. 
Pero cuando se nota además en los niños inquietud y mal humor casi constantes, entorpecimiento progresivo de las facultades intelectuales, un exterior triste y ceñudo, notable inclinación a la soledad, aversión a las distracciones ruidosas y posturas poco decentes, casi se puede estar seguro de que han contraído hábitos deplorables (AVENDAÑO; CARDERERA, 1850, p. 126-127).

Algo más de una década después, el maestro Agustín Rius presentaría un estudio de educación comparada elaborado en Francia por Baudouin con el objeto de resaltar la labor de los directores de los colegios galos en materia de gimnástica desensibilizadora para los adolescentes:

En fin los directores de establecimientos y los padres de familia atribuyen á los ejercicios gimnásticos efectos importantes que pueden suponerse. En efecto el predominio del aparato muscular se adquiere siempre en perjuicio de la sensibilidad esto es un hecho generalmente admitido pues bien á cierta época de la adolescencia se desarrolla instintivamente en el hombre un estímulo nervoso que irrita los órganos mas delicados y es causa á veces de un vicio cruel que ataca la vida en sus propias fuentes. Los ejercicios prolongados combaten directamente la sensibilidad causa primera del mal porque produce el cansancio de la fatiga nace el sueño y cuando el joven duerme profundamente no se ve asaltado de alucinaciones perniciosas (BAUDOUIN, 1866, p. 90-91).

Por la misma época, Manuel Benito Ruiz, considerando el caso de las niñas, también indicaba que el medio más eficaz contra la masturbación era "la gimnástica sostenida, bien ordenada y metódica" (RUIZ DE DIEGO, 1866, p. 25). A este respecto, aunque las referencias respecto de la prevención onanismo femenino son mucho menos frecuentes, se puede sostener que la incorporación de clases de gimnástica -sobre todo en algunos colegios femeninos de reconocida reputación- atendía a los fines de mantenimiento del debido pudor y recato que exigía la educación de las niñas.

En las postrimerías del siglo, el tópico no solo no se moderó sino que incluso cobró nuevos bríos al amparo de las cada vez más difundidas ideas regeneracionistas; particularmente, de aquellas expresiones más emparentadas con el darwinismo social y la corriente eugenésica. $E$ proceso de conformación y legitimación de la gimnástica como práctica saludable, lentamente gestado, parece eclosionar después de todo un siglo de avances y retrocesos y, sobre todo, de profundos cambios en las concepciones respecto del control y atención sanitaria de la población. Se incrementó exponencialmente la producción teórica sobre la gimnasia, se fundó la Escuela Central de Gimnástica (1887-1898) para la formación del profesorado de gimnasia en la Enseñanza Media, se declaró por primera vez la obligatoriedad de la gimnástica en la educación (R. D. de 13 de septiembre de 1898), etc. y quienes constituían el plantel de teóricos representativos de la época seguían apelando a los efectos antionanistas como una de las virtudes principales de la gimnasia. Esgrimieron tales efectos Salvador López Gómez (1873), David Ferrer Mitayna (1883), Francisco Pedregal Prida (1884) o Manuel Arellano Martínez (1894), todos ellos de remarcado renombre en la historia de la gimnástica en España.

El reconocido profesor de gimnastica Salvador López advertía que los jóvenes que se llevan por esta "resbaladiza pendiente" recaen en el "empobrecimiento físico adquirido, arrastrando a la vida miserable y llena de distintas y vergonzosas enfermedades" (LÓPEZ GÓMEZ, 1873, p. 207-208; 1894, p. 189).

David Ferrer, profesor de gimnástica, sostenía también que en la adolescencia: que produzca la sedación del sistema nervioso excitado, y en virtud de 
la necesidad del reposo de que va aquella acompañada, adormezca las pasiones 0 deseos exagerados con determinadas inclinaciones que son tan frecuentes como perjudiciales en esta edad (FERRER MITAYNA, 1883, p. 17-18).

El profesor Manuel Arellano, parafraseando al doctor Sebastián Busqué (1865), señalaba que la gimnástica servía para tratar la enfermedad de la masturbación "un hábito vicioso, repugnante en sí mismo y funesto por sus consecuencias" (ARELLANO MARTÍNEZ, 1894, p. 30).

El doctor Calatraveño, ocupándose de la educación física en la infancia, aún mantenía como uno de los argumentos para preservar la salud y contra los elevados índices de mortalidad infantil en España, advertía de la:

[...] altísima importancia que los padres, maestros, encargados y celadores de colegios vigilen cuidadosamente a los niños a fin de que entre los mismos no se desarrollen abominables vicios, que a más de ser inmorales, tantas víctimas ocasionan, tantos candidatos ofrecen a la tuberculosis y tanto contribuyen a la perdida de energías físicas de los niños (CALATRAVEÑO VALLADARES, 1892, p. 23).

En todo caso, a la gimnástica escolar antionanista de finales de siglo ya se le oponen nuevas y más racionales concepciones. En un momento en el que la racionalidad científicomédica y cultural había ganado terreno al clericalismo en el gobierno del cuerpo y que en toda Europa se asistía a un intenso movimiento de renovación pedagógica, aparecieron nuevos discursos, nuevas justificaciones que, sobre un terreno abonado, servirían para legitimar la impartición de la gimnasia en las escuelas: las mismas prácticas que habían impulsado y justificado el temor a la corrupción onanista, pero con nuevas y más racionales justificaciones.

En España, la iniciativa más sobresaliente en la que se conjuga el impulso racionalizador de la vida cultural y la renovación pedagógica la representa la Institución Libre de Enseñanza (ILE). Esforzados sus miembros en el desarrollo de un cambio higiénico, psicológico y pedagógico de orientación krausista y lejos de todo adoctrinamiento católico (BALLESTER; PERDIGUERO, 1998), inspiraron el movimiento de despenalización de la masturbación infantil. Por otra parte, frente al carácter disciplinario y mecánico de la gimnasia, la ILE vio en el juego al aire libre y en el deporte -que ya habían alcanzado en el resto de Europa cierto predicamento educativo- dos alternativas higiénico-pedagógicas congruentes con el ideario regeneracionista que, sin duda, habían abrazado.

Ello no quiere decir que la ILE se desprendiera ni radical ni súbitamente del tópico higiénico-moral. Desde las páginas de la BILE, Guimera aún apelaba a la práctica de los juegos para refrenar los impulsos sexuales:

Tienen en efecto los juegos una influencia moralizadora porque siempre que los muchachos se entregan a ejercicios fuertes, el aire libre y el movimiento apaciguan los sentidos y su imaginación, desean descansar y dormir y van a la cama soñando en los juegos del siguiente día lo cual constituye un poderosa salvaguarda contra las corrupción impidiendo unas veces que penetre y otras que extienda, cuando accidentalmente ha penetrado (GUIMERA, 1889, p. 36).

Pero, para la ILE, la principal causa de degeneración ya no era tanto el onanismo como simplemente la falta de ejercicio físico o de educación física en el hombre y en la mujer 
(LÓPEZ SERRA, 1998). Estamos en un momento en que el exceso de intelectualismo escolar, la pusilánime inactividad física, empezaba a preocupar más que las consecuencias del vicio solitario; empezaba a preocupar al menos lo suficiente como para impulsar un cambio en las justificaciones de una disciplina escolar que, en todo caso, ya había ganado la batalla de la pertinencia pedagógica: la educación física se había hecho acreedora de un lugar y de un tiempo dentro de la escuela. Así empieza a observarse cuando, por ejemplo, el pedagogo Pedro de Alcántara García, de orientación positivista influida por Fröebel y Spencer, presentó la educación física y la higiene escolar como un asunto genuinamente pedagógico propio, no tanto de médicos como de maestros (GARCÍA NAVARRO, 1879; 1882; 1886a; 1886b).

\section{A MODO DE CONCLUSIÓN}

A través de un proceso paulatino, lento pero acumulativo, de pequeñas intervenciones, de declaraciones y de disposiciones reglamentarias casi siempre coyunturales para responder a tal o cual fin concreto, a través de una cada vez más minuciosa organización de espacios y tiempos así como de medidas de vigilancia ad hoc, se fue conformando a lo largo del siglo XIX todo un sistema discursivo y práctico que, en su conjunto, obró al servicio de la institucionalización de la actividad gimnástica en los establecimientos escolares. "Nacido de planes, pero no planeado; movido por fines, pero sin un fin" que diría Norbert Elias (1990, p. 84). El complejo estratégico de preservación de la moral sexual de la juventud contribuyó de forma determinante a la configuración de la educación física escolar aunque ninguna de las actuaciones por separado, ni ninguno de los actores por sí mismo, tuviera siquiera en mente el propósito de crear una disciplina académica. Se trataba de establecer solo un régimen de medidas dirigidas a organizar la conducta de los alumnos y a proporcionar los medios preventivos contra las tendencias morbosas del siglo que, en todo caso, resultaron congruentes con los ideales sociales y económicos del momento. Y resultó que el mejor preservativo que unos y otros encontraron fue la permanente ocupación de los alumnos y la fatiga corporal: gimnástica moderada y continua para robustecer el cuerpo al servicio del alma y de la estabilidad social; parafraseando a Foucault (2012, p. 161), se trataría de medidas impuestas para responder a exigencias de coyuntura pero que en conjunto formaron parte de un proceso de transformaciones generales y esenciales que acabaron definiendo cierto modo de adscripción política y detallada del cuerpo, una nueva microfísica del poder; en el caso de la cruzada antionanista, transformaciones generales que acabaron configurando la educación física escolar como un dispositivo más de encauzamiento de la conducta.

\section{REFERENCIAS}

AGUILERA, FRANCISCO. Representación del señor D. Francisco Aguilera, conde de Villalobos, acerca de la formación de un Gimnasio Normal en Madrid. Madrid: Colegio de Sordomudos y Ciegos, 1845.

ÁLVAREZ GONZÁLEZ, Paz. Discurso en la Universidad Central. Madrid: Tip. de Vicente, 1863.

ARELLANO MARTÍNEZ, Manuel. Educación física: gimnástica higiénica - médica y ortopédica. Castellón: Tomas Boix, 1894.

AVENDAÑO, Joaquín; CARDERERA, Mariano. Curso elemental de pedagogía. Madrid: Victoriano Hernando, 1850. 
BALLESTER, Rosa; PERDIGUERO, Enrique. Salud e instrucción primaria en el ideario regeneracionista de la Institución Libre de Enseñanza. Dynamis, Acta Hispánica ad Miedicinae Scientiarum Historiam llustrandam, Barcelona, n. 18, p. 25-50, 1998.

BAUDOUIN, Jean Magloire. La enseñanza primaria y especial en Alemania. Barcelona: Juan Bastinos, 1866.

BUSQUÉ, Sebastián. Gimnástica, Higiénica, Médica y Ortopédica o el ejercicio considerado como medio terapéutico. Madrid: Imp. Manuel Galiano, 1865.

CALATRAVEÑO VALLADARES, Fernando. La educación física en la infancia. Madrid: Tip. Ricardo $\mathrm{Fe}, 1892$.

CLARET, Antonio María. Bálsamo eficaz para curar un sinnúmero de enfermedades de alma y cuerpo, ó sea Semana Santa para enmendarse ó preservarse del mal máximo y peste desoladora. Barcelona: Librería Religiosa, 1852.

CLARET, Antonio María. El colegial o seminarista teórica y prácticamente instruido. T. I. Barcelona: Librería Religiosa, 1856.

COLEGIO. La Esperanza, Madrid, p. 1, 19 ago.1865.

COLEGIO ESPAÑOL HAMILTONIANO. Reglamento interior del Colegio Español Hamiltoniano. Madrid: Compañía Tipográfica, 1838.

COLEGIO NAVAL MILITAR. Reglamento del Colegio Naval Militar. Madrid: Román Matute, 1848.

DEBREYNE, Pierre Jean Corneille. Ensayo sobre teología moral considerándola en sus relaciones con la fisiología y la medicina. Barcelona: Pons, 1855.

DESCURET, Jean Baptiste Félix. La medicina de las pasiones. 2. ed. Barcelona: Pablo Riera, 1857.

ELIAS, Norbert. La sociedad de los individuos. Barcelona: Península, 1990.

FERNÁNDEZ, Inés. Medicina y poder sobre los cuerpos. Thémata: Revista de Filosofía, Sevilla, n. 33, p. 191-198, 2004.

FERRER MITAYNA, David. De la utilidad general de la gimnasia y acción que ejercen sobre el organismo humano sus diferentes ejercicios. Barcelona: José Miret, 1883.

FIGUEROLA, Laureano. Manual completo de enseñanza simultánea, mutua y mixta: 0 instrucciones para la fundación y dirección de las escuelas primarias elementales y superiores. Madrid: A. Mateis Muñoz, 1842.

FONSSAGRIVES, Jean Baptiste. Tratado de higiene de la infancia. 2. ed. Madrid: A. Pérez Dubrull, 1887.

FOUCAULT, Michel. Vigilar y castigar: nacimiento de la prisión. Madrid: Biblioteca Nueva, 2012.

GACETILLA de la capital. El Observador, Madrid, p. 4, 12 ene. 1850.

GARCÍA NAVARRO, Pedro de Alcántara. De las teorías modernas acerca de la educación física. Madrid: J. Gil y Navarro, 1886a.

GARCÍA NAVARRO, Pedro de Alcántara. Manual teórico-práctico de educación de párvulos según el método de los jardines de infancia de F. Froëbel. Madrid: Colegio Nacional de Sordo-Mudos y Ciegos, 1879.

GARCÍA NAVARRO, Pedro de Alcántara. Teoría y práctica de la educación y la enseñanza. Madrid: Gras y Compañía, 1882. v. 5: De Educación Física.

GARCÍA NAVARRO, Pedro de Alcántara. Tratado de higiene escolar. Madrid: Hernando, 1886b.

GINÉ PARTAGÁS, Juan. Curso elemental de higiene privada y pública. Barcelona: Narciso Ramírez y Compañía, 1871. v. 1: Higiene privada. 
GINÉ PARTAGÁS, Juan. Tratado de higiene rural. Barcelona: José Tauló, 1860.

GONZÁLEZ, Julián. Discurso en que se prueba que la educación para ser completa y útil al individuo, a la familia a la nación y a la sociedad, debe ser enteramente real, positiva y práctica en todos sus ramos. Madrid: José María Alonso, 1850.

GOUX, Juan. Algunas palabras sobre la gimnasia médica y ortopédica. Madrid: T. Fortanet, 1866. GRASA PÉREZ, José Lorenzo. Discurso leído ante el claustro de la Universidad Central. Madrid: Manuel Rojas, 1861.

GRISOLLE, Augustin. Tratado elemental y práctico de patología interna. Madrid: Gaspar Roig, 1857. v. 2.

GUIMERÁ, llirio. Los ejercicios corporales. BILE, Madrid, n. 288, p. 33-37, 1889.

LAQUEUR, Thomas. Sexo solitario: una historia cultural de la masturbación. Buenos Aires: Fondo de Cultura Económica, 2007.

LLADÓ, Joaquín. Nociones de gimnasia higiénica. Barcelona: Juan Bastinos, 1868.

LÓPEZ GÓMEZ, Salvador. El gimnasio. Sevilla: R. Baldereque, 1873.

LÓPEZ GÓMEZ, Salvador. Manual de ejercicios gimnásticos. Sevilla: Gironés y Orduña, 1894.

LÓPEZ SERRA, Francisco. Historia de la educación física de 1876 a 1898: la institución libre de enseñanza. Madrid: Gymnos, 1998.

MADOZ, Pascual. Diccionario geográfico-estadístico-histórico de España y sus posesiones de ultramar. Madrid: [s.n.], 1850. v. 10.

MELLADO, Francisco de Paula. Enciclopedia moderna: diccionario universal de literatura, ciencias, artes, agricultura, industria y comercio. Madrid: Mellado, 1854. v. 27.

MONLAU, Pedro Felipe. Elementos de higiene privada: 0 arte de conservar la salud del individuo. Madrid: Pablo Riera, 1846.

MONLAU, Pedro Felipe. Elementos de higiene pública. Barcelona: Pablo Riera, 1847.

ORTEGA FERNÁNDEZ, Manuel. Discurso leído en la Universidad Central. Madrid: Francisco Hernández, 1866.

PEDREGAL PRIDA, Francisco. Gimnástica civil y militar. Madrid: M. Ginés Hernández, 1884.

PERDIGUERO GIL, Enrique; GONZÁLEZ DE PABLO, Ángel. Los valores morales de la higiene. El concepto de onanismo como enfermedad según Tissot y su tardía introducción en España. Dynamis: Acta Hispánica ad Miedicinae Scientiarum Historiam llustrandam, Barcelona, n. 10, p. 131-162, 1990.

PLAN DE EDUCACIÓN FÍSICA Y MORAL. Semanario Instructivo, Madrid, 13 de noviembre de 1830, p. 5-6.

QUINTANAS, Anna. Higienismo y medicina social: poderes de normalización y formas de sujeción de las clases populares. Isegoría, Madrid, n. 44, p. 273-284, 2011.

RENDU, Ambroise. Curso de pedagogía. Tarragona: A. Puigrubi y Canals, 1845.

RUIZ DE DIEGO, Manuel Benito. Discurso leído en el paraninfo de la Universidad Central en el acto solemne de recibir la investidura de Doctor en la Facultad de Medicina y Cirugía. Badajoz: Imp. de la Política, 1866.

SECCIÓN de anuncios. El Clamor Público, Madrid, p. 4, 8 mayo 1850.

SERAINE, Louis. Higiene física y moral de los niños. Madrid: Álvarez Hermanos, 1876.

SIMÓN PALMER, María del Carmen. La enseñanza privada seglar de grado medio en Madrid (1820-1868). Madrid: Instituto de Estudios Madrileños, 1972. 
TESTE, Alphonse. Tratado homeopático de las enfermedades agudas y crónicas de los niños. Toledo: Severiano López Fando, 1850.

TISSOT, Samuel Auguste D. L'onanisme: ou dissertation physique sur les maladies produites par la masturbation. Laussanne: Chapuis, 1760.

TORREBADELLA FLIX, Xavier. Del espectáculo acrobático a los primeros gimnasios modernos: una historia de las compañías gimnástico-acrobáticas en la primera mitad del siglo XIX en España. Aloma, Barcelona, v. 31, n. 2, p. 67-84, 2013a

TORREBADELLA FLIX, Xavier. Gimnástica y educación física en la sociedad española de la primera mitad del siglo XIX. Lleida: Universitat de Lleida, 2013b.

TORREBADELLA FLIX, Xavier. La educación física femenina en el período Isabelino (1833-1868): Teresa Castellanos de Mesa, primera profesora española de gimnástica. Ágora para la Educación Física, Valladolid, v. 15, n. 1, p. 20-39, $2013 \mathrm{c}$.

TORREBADELLA FLIX, Xavier. Las primeras tesis doctorales de la educación física en el espacio científico y profesional sobre la medicina española. Pecia Complutense, Madrid, n. 16, p. 58-88, 2012. TORRES, Francisco Jorge. Educación física o libro de la salud. Madrid: José María Alonso, 1853. VÁZQUEZ GARCÍA, Francisco; MORENO MENGÍBAR, Andrés. Sexo y razón: una genealogía de la moral sexual en España (Siglos XVI-XX). Móstoles: Akal, 1997.

VÁZQUEZ GARCÍA, Francisco; SEOANE CEGARRA, José Benito. España y la cruzada médica contra la masturbación (1800-1900): elementos para una genealogía. Hispania, Madrid, n. 218, p. 835-868, 2004.

VICENTE- PEDRAZ, Miguel; TORREBADELLA- FLIX, Xavier. La gimnástica como dispositivo antionanista en la conformación de la educación física escolar en el siglo XIX en España. La recepción del discurso. Movimento, Porto Alegre, v. 21, n. 4, p. 1037-1049, 2015.

VINAJA CABALLERO, Miguel. Discurso leído ante el claustro de la universidad Central. Madrid: Manuel de Rojas, 1860. 
